\title{
Development of MPPT Algorithm and Wind Rose Model for Wind Farm in Maharashtra
}

\author{
Krishnat U. Jadhav, Archana G. Thosar
}

\begin{abstract}
This work focuses on enhancements of the maximum power point tracking for wind energy village. This work also targeted on numerous variables like air density, wind speed and impression of other geographical regions specific ecological elements. The Incremental Conductance along with Fractional open Circuit Voltage algorithms are usually is much less fruitful and still has problem in determining perfect step-size. To eliminate such drawbacks we recommended Hybrid execution of MPPT algorithms for maximum power point tracking to achieve the best possible power operation. The algorithms are presented by using Matlab simulation. This paper also delivers results for wind farm for various climate conditions in Maharashtra region with wind rose analysis. The outcomes attained are ideal for equivalent weather conditions based on air density variations and Hybrid Algorithm execution can be applied to draw out maximum power point. Results shows that recommended method is more efficient maximum power point tracking method with less execution time for any renewable energy resources.
\end{abstract}

Keywords: MPPT algorithms, power optimization, wind energy, incremental conductance, wind rose, wind farm analysis.

\section{INTRODUCTION}

$\mathrm{R}$ enewable energy resources are upcoming lamp post for ecological energy generation. Wind energy transformation techniques require optimization for optimum usage. There are many researches taking place globally. Renewable energy generation using wind energy has emerged worldwide and has opened up significant new markets in electrical power generation. However, different factors that affect power quality performance of wind turbine (WT) applications such as wind speed fluctuation and use of power electronic based devices have been presented due to the rapid increase of WT installations [1]. However, according to geographical regions, wind energy transformation techniques ought to be localized regarding numerous variables like wind velocity, air denseness and impression of other ecological elements.

One of the ways to reduce the cost of photovoltaic systems is to maximize the power delivered to the load. On the other hand, changing the load leads to change the operating point of

Revised Manuscript Received on February 06, 2020.

* Correspondence Author

Mr. Krishnat Uttam Jadhav*, Assistant Professor, Department of BSH, Dr. Daulatrao Aher College of Engineering, Karad, India.

Dr. Archana G. Thosar, Professor, Department of Electrical Engineering, Government College of Engineering, Pune, India.

(c) The Authors. Published by Blue Eyes Intelligence Engineering and Sciences Publication (BEIESP). This is an open access article under the CC BY-NC-ND license (http://creativecommons.org/licenses/by-nc-nd/4.0/) the solar conversion system and causes deviation from the maximum power point (MPP) [2]. Similarly, Maximum power point tracking is a concern for wind energy generation too. Present Perturb and Observe algorithm has been noticed becoming the most efficient maximum power point tracking (MPPT) method for wind energy approaches due to its advantage. Existing research supported that two boost converters method transfers a maximum power of Wind Energy Conversion System (WECS) and Photo Voltaic (PV) system to DC link using Perturb and Observe algorithm [3]. On the other hand, the Incremental Conductance along with Fractional open Circuit Voltage algorithms are adaptable and simple in setup, despite the fact that usually are much less fruitful and still have troubles determining perfect step-size [4].

Therefore, to eliminate such drawbacks there is a need of new maximum power point tracking algorithm with increased precision and lasting to often transforming climate conditions. Therefore, this paper suggests Hybrid Algorithm and is built to assess MPPT for the best possible power operation. This paper also delivers analysis of wind village for various climate conditions in India region with wind rose analysis. The outcomes attained are ideal for equivalent weather conditions chart and Hybrid Algorithm might be applied to draw out maximum power point.

\section{MOTIVATION}

Numerous of literature is available for traditional MPPT approaches. But, it is important to study the worldwide geographical performances to compare proposed study. Hence, this paper evaluates specific literature based on applied MPPT approaches.

MPPT approaches provide a complicated execution procedure; also, they get afflicted by any kind of power loss because of wind velocity and air density changes. The convergence rate with the MPPT strategy is dependent upon the dimensions of the alteration in functioning point. An increased step dimension may monitor MPP more quickly, although it will likewise bring about higher power oscillations across the MPP. A smaller step dimension will decrease power oscillations close to MPP, although it'll need additional time to monitor the MPP. Commonly, the perturbation step dimension is within the range of $0.05-0.1$. The proposed research provides the automatic optimized step size which leads to high accuracy. 


\section{Development of MPPT Algorithm and Wind Rose Model for Wind Farm in Maharashtra}

\section{PROPOSED METHODOLOGY}

Based Based on the maximization of harnessed power, the MPPT algorithms are generally classified in indirect power controller (IdPC) as well as direct power controller (DirPC) [5].

The IdPC boosts the harnessed kinetic wind power ( $\left.P_{\text {windpower }}\right)$, it does not affect the electrical power output $\left(P_{\text {output }}\right)$, on other hands, the DirPChas a direct impact on power output which maximizes $P_{\text {output }}$.

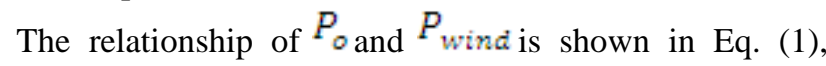
where $\eta_{\text {generator }}$ is the generator efficiency and $\eta_{\text {converter }}$ is the converter efficiency whichchangeswith the change in rotor speed. Hence, even when the optimal $P_{\text {wind }}$ is obtained, it cannot guarantee the optimal $P_{\text {o }}$.

$$
P_{\text {output }}=\eta_{\text {generator } \mathrm{x}} \eta_{\text {converter } \mathrm{x}} P_{\text {windpower }}
$$

The MPPT mainly shifts due to variable velocity. The characteristic is shown in figure 1 bellow to represent the impact of turbine power due to changing wind velocity. Hence, the present focus is to identify MMP with more accuracy. To understand the exact need for accuracy enhancement, this paper discusses various MPPT algorithms to develop the new modified hybrid algorithm. Such algorithm is proposed to build all advantages of direct power control algorithms to get the desired solution.

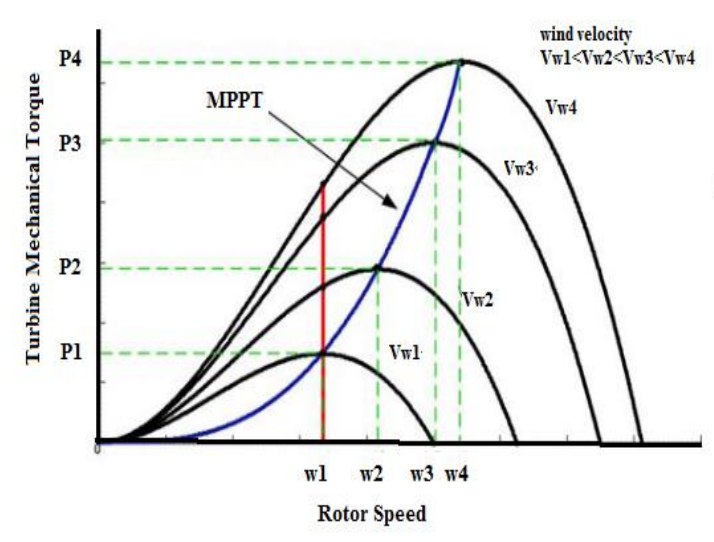

Fig. 1. Representation of power versus speed for various wind velocities [5]

Direct power controlled MPPT algorithms is usually subdivided into 3 forms, i. e., perturb and observe (P\&O) [6], incremental conductance (IC) and fractional open-circuit voltage (FoCV) [8]. This kind of methods can monitor MPPT without separating the wind system in the event of real-time assessment [9]. Incremental Conductance algorithm is self-sufficient of the requirement of devices and features of turbine and power generator, which in turn boosts the consistency and decreases the expense of the system. The turbine output power may be manifested as being a function of DC link voltage $V_{\text {de }}$. There is also an optimum $V_{\text {de }}$ $\left(V_{\text {ref }}\right)$ which often boosts output power of the turbine by considering instantly applying IC algorithm [7]. Because the power is corresponding to the product of current $I_{d e}$ and voltage $V_{d e}$, the calculation of this slope is given by:

$$
\frac{d P_{d e}}{d V_{d e}}=\frac{d\left(w_{i}\right) d e}{d V_{d e}}=i_{d e}+v_{d e} \frac{d i_{d e}}{d v_{d e}}
$$

$-(2)$

Hence, after solving the derivative for MPP we get,

$$
\frac{i_{d e}}{v_{d e}}+\frac{d i_{d e}}{d v_{d e}}=0
$$

The main criteria becomes the slope of power-voltage characteristic $(i / v+d i / d v)$ which ideally must be zero at maximum power point, it will be considered as a 'positive' if shifts towards the left side, and will be considered as a 'negative'if shift of point is at the right side of retrieved maximum power point. This is shown in flowchart represented in figure 2 below.

The above-mentioned equations represent that as an alternative to noticing for climate dependent variables like velocity and route of wind flow, the MPP may be monitored by searching for productivity power from the rectifier.

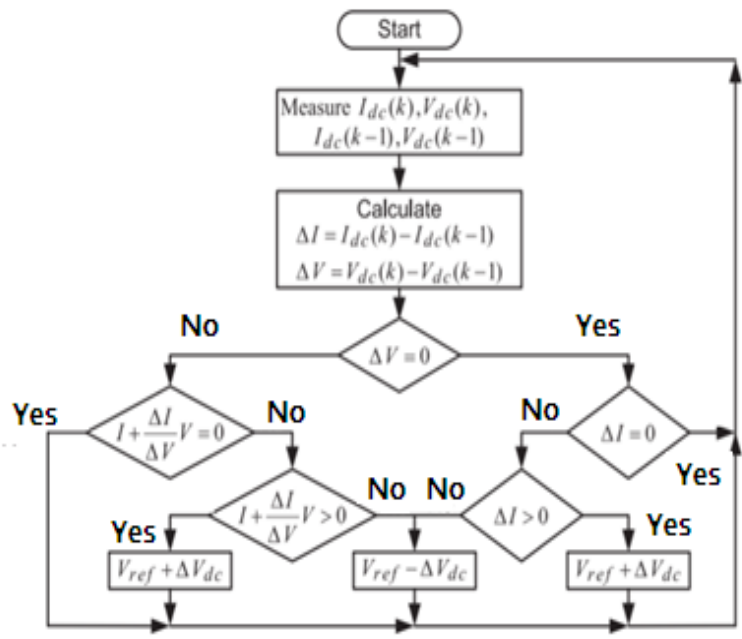

Fig. 2. Flowchart Incremental Conductance Algorithm

The improved IC algorithm [10,11] enhances the overall performance of the algorithm by taking into consideration a

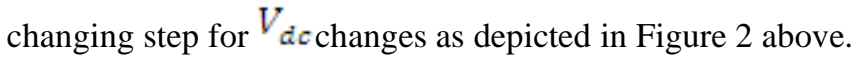
It instantly changes the particular step size to monitor the MPP in WES, which leads to improvement of system accuracy and reliability. The execution of Design Predictive control in wind generator MPPT controller boosts velocity and stability and as well mitigates the issue of oscillations

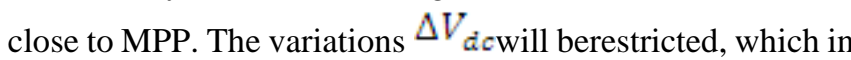
turn changes according to system layout variables and also the size of the generator. Bringing out changing steps in this particular algorithm brings about the functioning point to achieve the maximum power faster and decrease of power fluctuation close to MPP.In FoCV Algorithm, the fractional-order differentiator is normally used on signal control, adaptive management, active control, linear and also nonlinear responses management.

Published By:

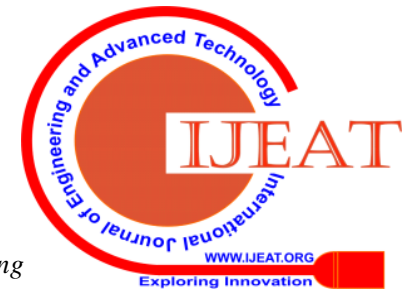


Presently, numerous processing software of fractional-order derivative is already recommended, based on the definition of Riemann-Liouville and Grunwald-Letnikov.

The near linear relationship between the voltage at maximum power $\left(V_{\text {mpp }}\right)$ and Open Circuit Voltage ( $\left.V_{\text {or }}\right)$ of the wind energy unit, under varying velocities, has given rise to the fractional $V_{\text {ocmethod [12]. }}$

$$
K_{1}=\frac{\mathbb{W}_{\text {MPP }}}{\mathbb{W}_{0 c}}
$$

Where,

$K_{1}$ is a proportionality constant. $K_{1}$ depends on the intended WES characteristics, it must be calculated initially. Further, determining $V_{\text {mpp }}$ and $V_{\text {oo }}$ for the specific WES at various velocities is accomplished. The value of $K_{1 \text { generally }}$ considered between the range 0.71 and 0.78 . With the knowledge of $K_{1}$ is, further $V_{\text {mpp }}$ is calculated by (Eq.4) and $V_{\text {ov }}$ is recorded periodically by pausing the operation of the power converter. Figure 3 depicts the flowchart for execution of fractional open-circuit based MPPT Algorithm.

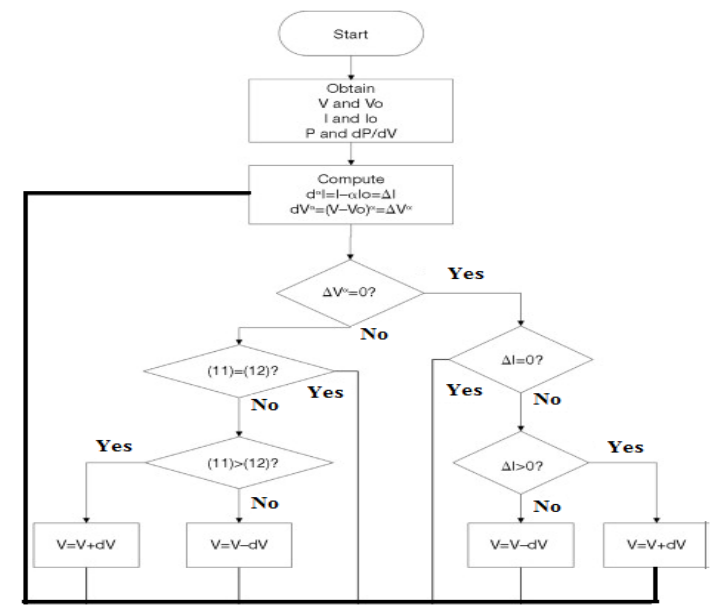

Fig. 3. Flowchart Fractional open-circuit voltage Algorithm

Further, for real-time variable wind velocity, we conducted wind rose analysis which is discussed in next section.

For simulation analysis we used MATLAB R2017a Simulink to develop the simulated WPS architecture also to design the control technique. Figure 6 demonstrates the simulation diagram of the WPS. The P\&O, IC, and FoCV are compared by means of 3 MPPT algorithms for duty cycle control of various switching realignment controls.

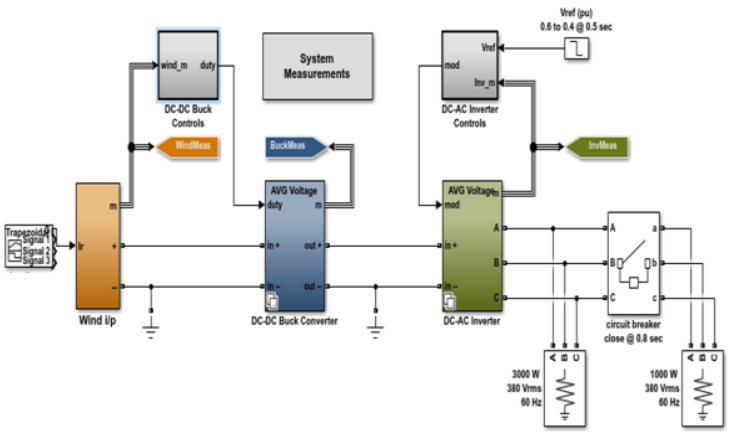

Fig. 4. Block diagram for MPPT algorithm performance evaluation.

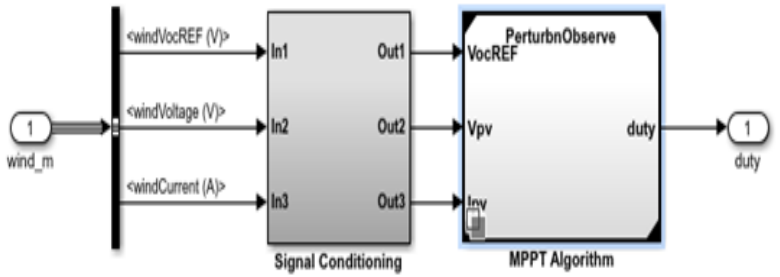

Fig. 5. Perturbation and Observation block for wind power system MPPT

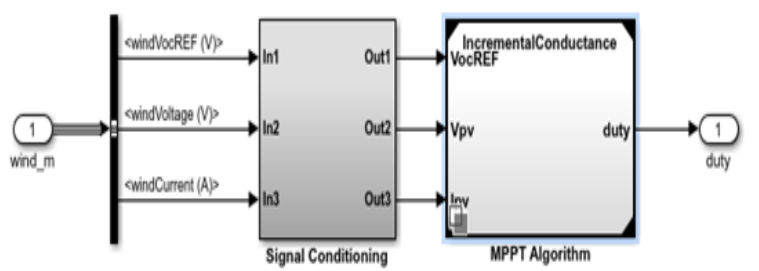

Fig. 6. Incremental Conductance block for wind power system MPPT

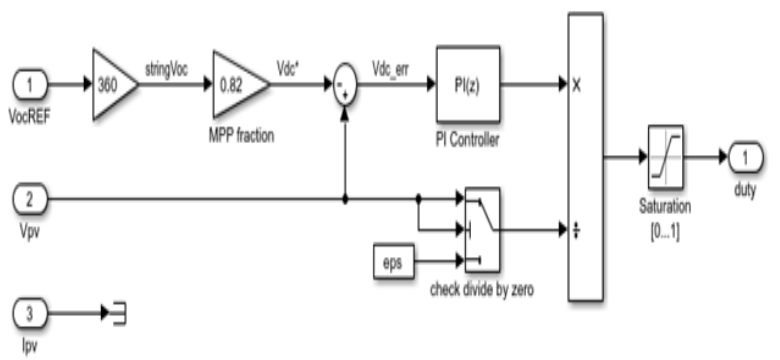

Fig. 7. Fractional Open Circuit Voltage block for wind power system MPPT

This specific analyze employed MATLAB R2017a Simulink to develop the design and controller for WPS and offered the PMSG-based WPS simulation.

\section{RESULT AND DISCUSSION}

The simulation designed and executed to compare the P\&O, IC, and FoCV MPPT algorithm performance at constant wind velocity and varying wind velocity to identify most efficient MPPT algorithm. Initially, wind velocity kept constant at $10 \mathrm{~m} / \mathrm{s}$, as shown in following Figure 10 . The $\mathrm{P} \& \mathrm{O}, \mathrm{IC}$, and FoCV proposed in this paper are analyzed and compared using this wind velocity.

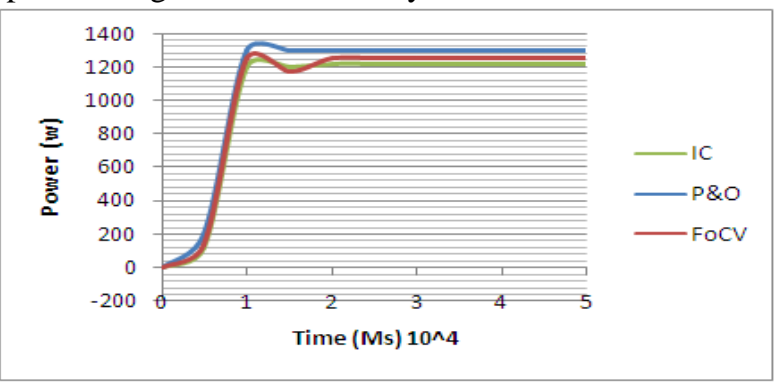

Fig. 8. Comparison of $P \& O, I C$ and FoCV at wind speed of $10 \mathrm{~m} / \mathrm{s}$

Published By:

Retrieval Number: C5368029320/2020@BEIESP 


\section{Development of MPPT Algorithm and Wind Rose Model for Wind Farm in Maharashtra}

$\mathrm{P} \& \mathrm{O}$ algorithm is analyzed by simulation execution at constant wind velocity. The output results for voltage, current and, power is shown in subsequent figure 9.

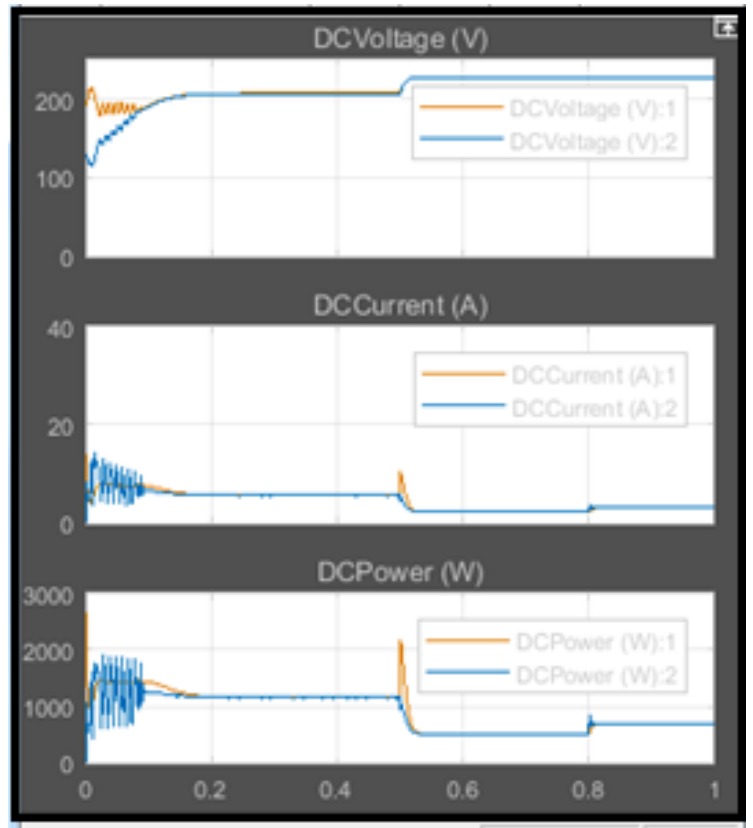

Fig. 9. MPPT simulation output representation at constant wind velocity

By increasing the voltage reference to 1 per unit allows the inverter to extract the maximum power from the Wind Turbine action. Refer figure 10 below.

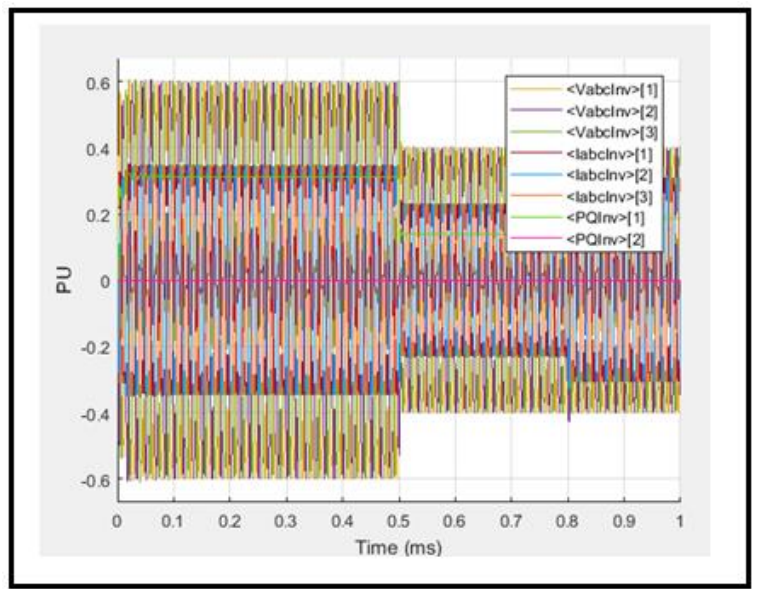

Fig. 10. MPPT simulation output representation for variable wind velocity

As per recorded results, Perturbation and Observation algorithm is with enhanced performance for identification of maximum power point tracking over Fractional Open Circuit Voltage and Incremental Conductance MPPT algorithm.

With changing air density and wind speed (and wind direction) the power obtained for wind energy conversion system is computed considering actual readings for period of 2 years. As shown in figure 1, the 'Power2' recorded during rainy season found high however 'Power1' tested during transit period of summer and rainy season found very low as well as uneven. 'Power3' which is tested during transit period of rainy season and winter noted as a substantially stable power output. We used wind rose [13, 14] analysis for proposed study. season

Power2: tested during Rainy season

Power3: tested during transit period of Rainy season and winter

Power4: tested during winter season

Power5: tested during transit period of winter and throughout summer

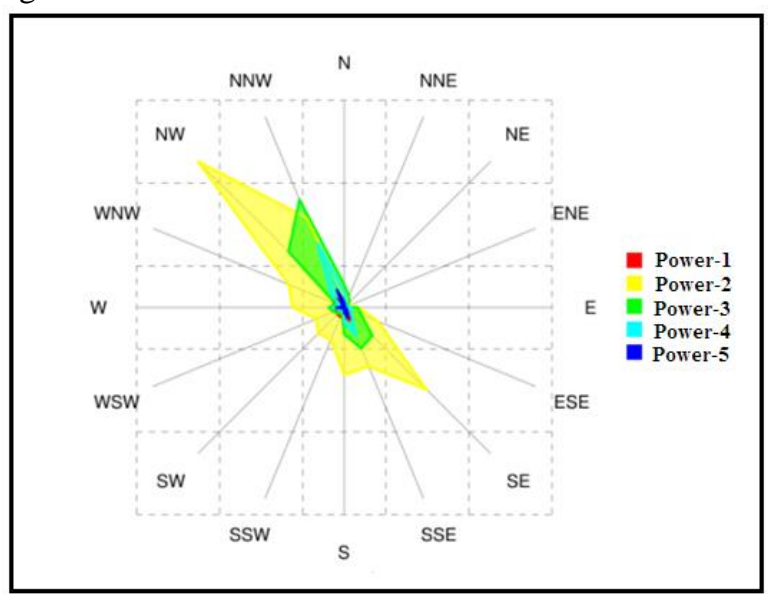

Fig. 11. Representation of data interpretation based on onsite observations

With recorded readings, MPPT algorithms namely Perturb and Observe, Incremental Conductance and Fractional open Circuit Voltage are tested using Matlab 2017a simulation.

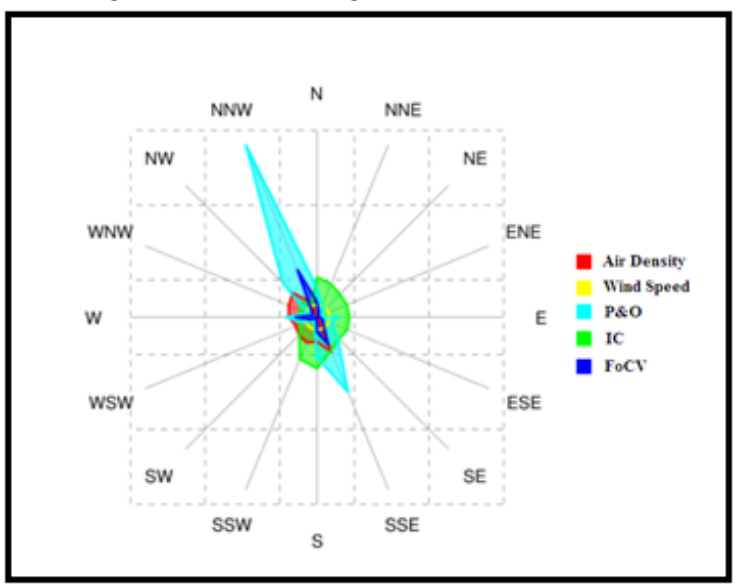

Fig. 12. Comparison of MPPT algorithms for input Air density and wind speed

The performance evaluation shows that Perturb and Observe gives more accurate MPPT irrespective of air density and wind speed. Whereas Incremental Conductance and Fractional open Circuit Voltage are less productive.

\section{CONCLUSION}

In this paper, direct power control MPPT algorithms outlined together with experimental analysis and also Matlab simulation control design. Paper mentioned perturbation and observation, Incremental conductance and Fractional open-circuit voltage techniques which in turn were used with buck converter for experimental evaluation and the overall performance is analyzed by employing control circuit,

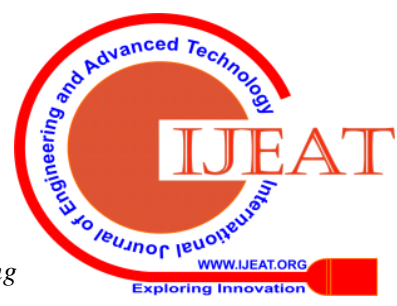


a driver circuit, and power circuit. The wind rose analysis results and simulation results are shows that $\mathrm{P} \& \mathrm{O}$ algorithm provides more accurate tracking of maximum power point as compared to incremental conductance and fractional open circuit voltage algorithm. The scope can be extended as a future development to design a hybrid wind rose algorithm to utilize merits of all MPPT algorithms for wind farm studies.

\section{REFERENCES}

1. Karami, Nabil, Nazih Moubayed, and Rachid Outbib. "General review and classification of different MPPT Techniques." Renewable and Sustainable Energy Reviews 68 (2017): 1-18.

2. Kumar, K., N. Ramesh Babu, and K. R. Prabhu. "Design and analysis of an integrated Cuk-SEPIC converter with MPPT for standalone wind/PV hybrid system." International Journal of Renewable Energy Research (IJRER) 7.1 (2017): 96-106.

3. Chen, Jian, et al. "Design of robust MPPT controller for grid-connected PMSG-Based wind turbine via perturbation observation based nonlinear adaptive control." Renewable energy 134 (2019): 478-495.

4. Abdalla, Omer, Hegazy Rezk, and Emad M. Ahmed. "Wind driven optimization algorithm based global MPPT for PV system under non-uniform solar irradiance." Solar Energy 180 (2019): 429-444

5. Karabacak, Murat. "A new perturb and observe based higher order sliding mode MPPT control of wind turbines eliminating the rotor inertial effect." Renewable energy 133 (2019): 807-827.

6. Linus, Rajin M., and Perumal Damodharan. "Maximum power point tracking method using a modified perturb and observe algorithm for grid connected wind energy conversion systems." IET Renewable Power Generation 9.6 (2015): 682-689.

7. Mahmudi, Irwan, et al. "Modified firefly algorithm for maximum power point tracking of a small stand alone wind power system." 2016 International Seminar on Intelligent Technology and Its Applications (ISITIA). IEEE, 2016.

8. Samman, Faizal Arya, Wahyu H. Piarah, and Zuryati Djafar. "Variable Step-Size Decremented Window-Size Scanning-based MPPT Algorithms for Thermoelectric Generator Systems." 2018 2nd International Conference on Applied Electromagnetic Technology (AEMT). IEEE, 2018.

9. Lahfaoui, Badreddine, et al. "Real time study of P\&O MPPT control for small wind PMSG turbine systems using Arduino microcontroller." Energy Procedia 111 (2017): 1000-1009.

10. Wang, Xiao, et al. "Implementations and evaluations of wind turbine inertial controls with FAST and digital real-time simulations." IEEE Transactions on Energy Conversion 33.4 (2018): 1805-1814.

11. Lahfaoui, Badreddine, et al. "Implementation of a Real-Time MPPT of Hybrid Renewable Energy System Composed of Wind Turbine and Solar PV Cells." International Conference on Electronic Engineering and Renewable Energy. Springer, Singapore, 2018.

12. Gupta, Shikha, Omveer Singh, and M. A. Ansari. "Maximum Power Point Tracking Techniques for Photovoltaic System: A Review." Advances in Signal Processing and Communication. Springer, Singapore, 2019. 455-465.

13. Akour, Salih N., et al. "Experimental and theoretical investigation of micro wind turbine for low wind speed regions." Renewable energy 116 (2018): 215-223.

14. Wang, Ni, et al. "Optimal reactive power dispatch of a full-scale converter based wind farm considering loss minimization." Renewable energy 139 (2019): 292-301. 